\title{
EDITORIAL
}

\section{Derecho del Trabajo y Covid-19: tiempos inciertos}

\author{
Jesús R. Mercader Uguina* \\ Catedrático de Derecho del Trabajo y la Seguridad Social \\ Universidad Carlos III de Madrid
}

doi: https://doi.org/10.20318/labos.2020.5536

"Si el fundamento de nuestra certeza es la experiencia,
debe tratarse obviamente, de la experiencia pasada"
(L. Wittgenstein, Sobre la certeza, $\$ 275$ )

\section{Tiempos inciertos}

Las reflexiones que hasta hace unos meses se hacían sobre el desarrollo humano no podían ser más positivas. Se hablaba de una nueva era de las luces, del "Homo deus", superador de las guerras, del hambre y de las enfermedades. Y, en este nuevo mundo feliz, nos habíamos empezado a preocupar por los efectos que la intensificación de los procesos de robotización y la incorporación de nuevas tecnologías podrían ejercen como fuerza de expulsión de mano de obra y de reducción de la fuerza de trabajo. La única sombra que se cernía sobre nuestra idílica realidad - "No sabíamos que éramos felices", ha titulado un artículo periodístico- era la del desempleo tecnológico que empezaba a cernirse amenazadora sobre unos mercados de trabajo bastante debilitados como consecuencia de las crisis económicas que se han venido sucediendo y que, a duras penas, empezábamos a superar.

$Y$ ha sido en este momento en el que ha hecho acto de presencia la pandemia de COVID-19 y hemos vuelto de repente nuestra mirada a la naturaleza. La persona ha dejado de ser la medida de todas las cosas. El virus se está transmitiendo a la economía y a la sociedad a una velocidad inusitada, afectando tanto a la actividad productiva como a la demanda y al bienestar de los ciudadanos. Las actuaciones desarrolladas para reducir la pérdida de vidas humanas han conducido a la mayoría de las economías a una paralización de parcelas importantes de la actividad y, por tanto, a una caída profunda de la riqueza económica. La crisis sanitaria global está dando paso a una crisis económica también global que ahonda en la crisis de empleo latente que empezábamos a atisbar. En estos tiempos en los que estamos atravesando la incertidumbre y donde las soluciones a los problemas que se van planteando se adoptan día a día, el marco jurídico ha sido objeto de intensas transformaciones para adaptarse a este nuevo escenario.

De manera brusca nos hemos puesto frente a frente con un problema desconocido que ha transformado nuestro modo de vida y que, de manera, ahora sí, plenamente disruptiva, nos ha

*jesus.mercader@uc3m.es 
situado en el inicio de una nueva era. Quizá el ser humano nunca ha sido tan consciente a lo largo de su historia de un tránsito tan radical como éste. Y si la sociedad se transforma, el Derecho social, inevitablemente, también lo hace. Un Derecho social entendido, como recordaba Radbruch, como realidad jurídica no dedicada a "un individuo despojado de su individualidad, de su propia manera de ser, de su condicionamiento social, sino que se basa en el hombre concreto inserto en determinadas condiciones sociales".

Este Derecho social nacido en la situación de emergencia sanitaria se encuentra lleno de paradojas. En él, parafraseando a Dworkin, hemos visto aparecer un Gobierno y una Administración "Hércules" obligados a asumir de forma plena e integral el papel regulador, aplicador y de control de la normativa excepcional nacida a raíz de la declaración del estado de alarma. Un Derecho sin jueces. Un tiempo, también, en el que se han dado la mano el sector primario y la tecnología más avanzada para dar respuesta a las necesidades de la población. Y es que, no se olvide, el Real Decreto-ley 13/2020, de 7 de abril, por el que se adoptan determinadas medidas urgentes en materia de empleo agrario se dirigió a garantizar la disponibilidad de mano de obra para hacer frente a las necesidades de agricultores y ganaderos, mientras que el teletrabajo y las más avanzadas técnicas de control personal y biométrico se han puesto sobre la mesa como instrumentos de conservación del empleo y como garantía de la salud de las personas. Una época en la que, en fin, la idea de flexiseguridad parece haber alcanzado un pleno equilibrio a través, por un lado, del atesoramiento del empleo a través de las suspensiones y reducciones del tiempo de trabajo y, por otro, del desarrollo de políticas públicas que han buscado garantizar rentas suficientes a los empleados y mecanismos de tutela para las empresas que impidan su desaparición en un escenario cuya evolución resulta impredecible. $\mathrm{O}$ que, si predecible, nos augura una recuperación larga y con una caída del Producto Interior Bruto (PIB) que este año podría llegar a ser de hasta un $15 \%$, si nos atenemos a los recientes informes del Banco de Espańa o del Fondo Monetario Internacional.

Sobre estas bases conviene detener el paso, alzar la mirada y hacer breve balance de lo sucedido en los últimos meses.

\section{COVID-19: La incertidumbre se instala en el ordenamiento laboral}

La crisis sanitaria ha llevado consigo la necesidad de adoptar medidas extraordinarias en el sistema jurídico hasta el punto de operar una auténtica transformación en su interior. La piedra angular de este Derecho excepcional se encuentra en la declaración del estado de alarma. Las medidas introducidas por el RD 463/2020, de 14 de marzo, por el que se declara el estado de alarma para la gestión de la situación de la crisis sanitaria ocasionada por el COVID-19 (en adelante, "RD. 463/2020"), una disposición animada por el propósito de evitar al máximo el contacto o la cercanía interpersonal, ha llevado consigo una red normativa tejida por el Gobierno que ha partido del valor legal de la normativa de declaración del estado de alarma pues, como se ocupó de dejar sentado la STC 83/2016 "aunque formalizada mediante decreto del Consejo de Ministros, la decisión de declarar el estado de alarma, dado su contenido normativo y efectos jurídicos, debe entenderse que queda configurada en nuestro ordenamiento como una decisión o disposición con rango o valor de ley. Y, en consecuencia, queda revestida de un valor normativo equiparable, por su contenido y efectos, al de las leyes y normas asimilables cuya aplicación se puede excepcionar, suspender o modificar durante el estado de alarma”.

Pero, desde esa cúspide, la declaración del estado de alarma ha llevado consigo una auténtica avalancha normativa derivada de la necesidad de poner en marcha a contrarreloj un marco legal para afrontar la pandemia desde un enfoque multifactorial en el que debían coordinarse criterios 
sanitarios, económicos, laborales, sociales y jurídicos. Una transversalidad que ha llevado consigo, en ocasiones, una pluralidad de fuentes de regulación procedente de las también diferentes Administraciones implicadas y que, desde también distintas perspectivas, en la regulación, ha dado lugar a criterios de actuación no siempre coincidentes. ¿Cómo podemos de otro modo leer las relaciones entre la norma laboral que representa el Real Decreto-ley 8/2020 de 17 de marzo, de medidas urgentes extraordinarias para hacer frente al impacto económico y social del COVID-19 (en adelante, "RDL 8/2020") y la sanitaria del Real Decreto-ley 21/2020, de 9 de junio, de medidas urgentes de prevención, contención y coordinación para hacer frente a la crisis sanitaria ocasionada por el COVID-19 (en adelante, "RDL 21/2020")?

Por ello, si buscamos en el sistema de fuentes del COVID-19 el instrumento normativo más característico, sin duda, éste ha sido el Real Decreto-ley. Lógica consecuencia de la absorción por el ejecutivo del práctico monopolio de la producción normativa. El Decreto-ley ha pasado a convertirse en el instrumento normativo habitual para gestionar la crisis económica, desplazando a la forma jurídica de ley, lo que supone dejar en un discreto segundo plano la actuación parlamentaria. Es el efecto de la llamada "hipostenia legislativa", que supone esencialmente un desplazamiento del poder desde las instancias legislativas a las gubernativas. Ejemplo de ello es el largo listado de estas disposiciones que se han sucedido a lo largo de los últimos meses. Un camino normativo que se inauguró con el Real Decreto-ley 6/2020, de 10 de marzo, por el que se adoptan determinadas medidas urgentes en el ámbito económico y para la protección de la salud pública y que alcanza, por el momento, hasta el Real Decreto-ley 24/2020, de 26 de junio, de medidas sociales de reactivación del empleo y protección social del trabajo autónomo y de competitividad del sector industrial (en adelante, "RDL 24/2020").

Y, junto a ellos, centenares de disposiciones han dado cobertura a esta realidad adoptando formas múltiples y que han ido, de mayor a menor rango jurídico, desde los ya citados Decretos leyes hasta los decretos, incluidos el de alarma y sus prórrogas; las órdenes ministeriales; las resoluciones de ministerios; instrucciones; acuerdos, etc. Una pluralidad cuya correcta aprehensión para el ciudadano medio es prácticamente imposible. A ellos se han unido las disposiciones autonómicas que han ido marcando rumbos propios en distintas materias. Un ejemplo de ello en el espacio social ha venido de la mano, por ejemplo, de la importante cuestión que afecta a tantos miles de trabajadores, cómo fue la relativa a la procedencia o no de incluir a los fijos discontinuos pendientes de llamamiento en los ERTES. Instrucciones y Circulares de distintas Comunidades Autónomas ligadas estrechamente al sector turístico (Cataluña, Valencia, Islas Baleares) vinieron a establecer, ante las dudas procedentes de la normativa estatal, que el criterio a seguir era el del llamamiento y el de la inclusión en los ERTES. Dudas competenciales al margen, lo que está claro es que la hiperproducción jurídica ha generado incertidumbre en el panorama jurídico.

La permanente sucesión de normas y su ingente volumen también han contribuido a una sensación de inseguridad. La motorización normativa de los últimos meses ha dado lugar a un sinfín de disposiciones continuamente alteradas en las que, en muchas ocasiones, parecía que se estaba buscando un camino más que se tuviera conciencia de por cuál se andaba. A ello ha contribuido la circulación de borradores, textos previos, declaraciones de prensa que eran interpretados por los agentes jurídicos como atípicas fórmulas prelegislativas que, en muchos casos, se desvanecían cuando tocaban la tierra firme del Boletín Oficial del Estado. Todos recordamos el día y la noche en la que se publicó el RDL 10/2020, de 29 de marzo (en adelante, "RDL 10/2020"), que regula el permiso retribuido recuperable de aplicación obligatoria a las personas trabajadoras que prestan servicios en empresas e instituciones, públicas y privadas. ¿Cuántos borradores circularon por las redes sociales ese día? ¿Cuántas previsiones se vieron frustradas cuando a las 23.40 del domingo 29 de marzo vio la luz la norma y su Anexo determinó las actividades que se consideraban "esenciales"? 
Pero los episodios de duda se han sucedido. Pongamos otro ejemplo para comprobar que estas sensaciones poseen base real. En la versión original publicada en el BOE de 18 de marzo de 2020, la Disposición Transitoria primera del RDL 8/2020, que establecía las reglas transitorias para los ERTES celebrados antes del 18 de marzo, tenía una redacción. Diez días después, el 28 de marzo de 2020, se publicaba el Real Decreto-ley 9/2020, de 27 de marzo, por el que se adoptan medidas complementarias, en el ámbito laboral, para paliar los efectos derivados del COVID-19 (en adelante, "RDL 9/2020"), que alteraba el texto inicial. Y, con efectos 2 de abril de 2020, el Real Decreto-ley 11/2020, de 31 de marzo, por el que se adoptan medidas urgentes complementarias en el ámbito social y económico para hacer frente al COVID-19 (en adelante, "RDL 11/2020") (cinco días después de la anterior reforma y catorce después de la primera), vuelve a modificar su contenido. Seguramente el Gobierno y el Ministerio de Trabajo y Economía Social tenían serias y fundadas razones para proceder a aquellos cambios, entre ellas sin duda la rapidez con que las circunstancias se iban sucediendo en aquellos momentos. Pero la pregunta que surgía era inmediata: ¿Tanto cambiaron las cosas en 14 días para que una norma transitoria como la referida fuera objeto de tres redacciones diferentes? ¿Dónde queda la seguridad jurídica para los trabajadores afectados por los ERTES que tuvieron en ese breve período hasta tres regímenes jurídicos diferenciados (Del 18 de marzo al 28 de marzo; del 28 de marzo al 2 de abril y del 2 de abril en adelante)?

Otra de las singularidades de este peculiar sistema de fuentes del COVID-19 ha sido el recurso a los más diversos instrumentos de interpretación en los que Gobierno y Administración han actuado como un sistema autoreferenciado a través de diversas fórmulas interpretativas en ausencia de la intervención judicial: Guías del Ministerio de Trabajo y Economía Social; Oficios de la Dirección General de Trabajo; Criterios Interpretativos del Organismo Estatal Inspección de Trabajo y Seguridad Social o los Boletines de Noticias Red de la Tesorería General de la Seguridad Social. Un Derecho excepcional sin jueces que marquen rumbos o que lo harán cuando la experiencia normativa se haya agotado o esté (deseemos) próxima a hacerlo.

Los defectos de técnica legislativa tienen preciso engarce con la seguridad jurídica. Y ello porque la seguridad jurídica, en tanto que valor estrechamente ligado a los Estados de Derecho, se presenta, en su acepción subjetiva, encarnada por la certeza del Derecho, como proyección de la función de "previsibilidad" en tanto que garantía de la planificación de las operaciones sociales y económicas. Y, ¡cómo podemos, tener seguridad si tenemos que rebuscar en cada nueva reforma para conocer el régimen que finalmente tendrá una regulación? Quizá sea exigir demasiado a las normas en tiempos tan turbulentos.

Otro terreno para la duda es el relativo a la vigencia de la normativa de excepción. El rebuscado sistema de determinación de la misma ha alcanzado cotas de innecesaria complejidad en muchos casos derivada del hecho de que una medida nacida bajo el paraguas del estado de alarma pueda prolongarse más allá del mismo. Tómese como ejemplo de estas atormentadas fórmulas el art. 5 RDL 8/2020, que establece el carácter preferente del trabajo a distancia, y que "se mantendrá vigente durante los dos meses posteriores al cumplimiento de la vigencia prevista en la DF 10.1 RDL 8/2020 modificado por la Disposición Final 1.17 del RDL 11/2020”. La regulación nos plantea una primera exigencia interpretativa: ¿La prórroga es de dos meses o de tres desde finalizado el estado de alarma? Leamos lo establecido por la disposición que se nos indica: "Con carácter general, las medidas previstas en el presente real decreto-ley mantendrán su vigencia hasta un mes después del fin de la vigencia de la declaración del estado de alarma”. En resumen, el plazo es de tres meses (el mes de prolongación previsto en DF 10.1 RDL 8/2020 modificado por la Disposición Final 1.17 del RDL 11/2020 más los dos meses que incorpora ahora el RDL 15/2020). No hubiera sido más fácil decir, como hace la nota informativa de la ITSS, que "La duración de esta prórroga es de tres meses tras la finalización del estado de alarma”. 
Y en este río revuelto, y aprovechando que el Pisuerga pasa por la hermosa Valladolid, se reforma el régimen de clases pasivas por el Real Decreto-ley 15/2020, de 21 de abril, de medidas urgentes complementarias para apoyar la economía y el empleo. ¿ Realmente resolver el tema era tan perentorio como para incluirlo en un Real Decreto-Ley, una norma en teoría reservada para casos de urgente necesidad? Una modificación silenciosa pero que, a largo plazo, llevará consigo importantes cambios. O, también, por no se sabe qué razones, la Disposición final $5^{\text {a }}$ del RDL 19/2020, de 26 de mayo, incluye un nuevo apartado 11 en el art. 33 ET (referido al régimen jurídico del FOGASA). ¿Será el silencio administrativo que tanto ha dado que hablar en el caso de los ERTES por fuerza mayor el que se refleja en esta disposición? Otro caso es, también, la modificación del art. 8 ET como consecuencia de la transposición de la Directiva (UE) 2017/159 del Consejo, de 19 de diciembre de 2016, por la que se aplica el Acuerdo relativo a la aplicación del Convenio sobre el trabajo en la pesca de 2007. O, en fin, la nueva redacción del art. 29.1 a) de la 23/2015, de 21 de julio, Ordenadora del Sistema de la Inspección de Trabajo y Seguridad Social. Ambas modificaciones han venido de la mano del RDL 24/2020.

A ello se ha unido el diálogo social, instrumento imprescindible en una situación como la que vivimos, que está dando a luz a importantes resultados (I y II Acuerdo en Defensa del Empleo), sobre la base de que la referida interlocución constituye, en palabras de la Exposición de Motivos del RDL 24/2020, "pieza fundamental para la reconstrucción y el fortalecimiento del mercado de trabajo, con el objetivo de conseguir una recuperación eficiente, pero también justa, equitativa, inclusiva y con vocación de futuro". Estos acuerdos están creando una auténtica red permanente para la gestión negociada de la crisis. Muestra de ello es la Comisión de Seguimiento tripartita laboral creada por la Disposición Adicional Segunda del RDL 18/2020 o las vías de diálogo abiertas por las Disposiciones Adicionales tercera, cuarta y quinta del RDL 24/2020. Una manifestación más del carácter pluralista de nuestra sociedad (art. 1.1 CE) que, hace que estos cauces, como dijera la STC 39/1986, en relación con las comisiones del AES, operen "como instancias para prolongar en el tiempo el propio proceso de intercambio que condujo al pacto tripartito -y que es considerado en sí como un valor que debe ser promocionado- (...)". En suma, una naciente neoconcertación social que ha tenido que venir de la mano del COVID-19 pero que siempre debe resultar bienvenida.

En suma, la declaración del estado de alarma ha traído consigo una regulación laboral especial y temporal llamada a desvanecerse si, finalmente, se pone fin a la pandemia, cuestión de momento también incierta. La realidad es que, como hemos visto, a lo largo de los últimos meses se han venido sucediendo numerosas disposiciones nacidas de la acelerada necesidad de dar respuesta inmediata a las situaciones que derivaban de la "hibernación" de nuestra economía y, por extensión, de nuestro mercado de trabajo. Un sistema jurídico ad hoc que ha buscado ser flexible y, por tanto, adaptable a las cambiantes y desconocidas necesidades que se sucedían pero que, como causa o como consecuencia de ello, ha abierto un verdadero océano de dudas y problemas de no siempre fácil respuesta.

\section{La flexibilidad laboral en la fuerza mayor: los Expedientes de Regulación Temporal de Empleo}

Pero la lógica adaptativa no solo ha operado en el plano de las fuentes. La misma se ha trasladado también, como era de esperar, a la de las instituciones que han sido objeto de regulación. Buen ejemplo de ello es la reformulación conceptual que ha sufrido la noción de fuerza mayor. Si, como regla general, la construcción dogmática de la fuerza mayor se ha construido sobre realidades que de manera imprevisible e instantánea transformaban el estado de cosas preexistente, la derivada del COVID-19 ha mostrado notables singularidades por su carácter variable y asimétrico. Una fuerza 
mayor de extensión variable (total o parcial) y cuyos rasgos diferenciadores en muchos casos son difíciles de separar de las causas económicas, técnicas, organizativas y productivas. En suma, una fuerza mayor mestiza en la que se traban las sangres de ambas fórmulas.

Desde el punto de vista laboral, la respuesta institucional a la crisis derivada de la emergencia sanitaria ha sido la conservación del empleo y el camino seguido han sido los Expedientes de Regulación Temporal de Empleo (en adelante, "ERTES”). Las suspensiones y las reducciones de jornadas han sido el camino seguido para atenuar las consecuencias derivadas del estado de alarma y, por extensión, el mecanismo de tutela laboral derivado de la necesidad de confinar en sus domicilios a la práctica totalidad de los ciudadanos. Una solución generalizada en Europa. A finales de abril de 2020, estos programas cubrían a más de 42 millones de trabajadores en la UE27 (cerca del 27\% del total). Suiza, Francia, Italia y Luxemburgo protegían ya entre un 40 y un $50 \%$ de sus trabajadores con este tipo de instrumento. Espańa, con una tasa de cobertura estimada con la información disponible en estas fechas del $24.1 \%$, se situaría a menos de 3 puntos de Alemania, cifra muy similar a las del Reino Unido y Holanda y muy por encima de las tasas estimadas para los países escandinavos. En el caso de España, los 3,4 millones de trabajadores cubiertos por ERTE a finales de abril de 2020 equivalen a la suma de todos los trabajadores con expedientes de suspensión de contrato desde inicio del año 1993, es decir, en los últimos 27 años (como señalan F. FELGUEROSO y M. JANSEN, ¿Qué nos enseña la evidencia sobre ERTEs?, Nada es gratis, 3 de junio de 2020).

Durante la segunda quincena de marzo, primero el RDL 8/2020 y, después, el RDL 9/2020 vinieron a establecer un conjunto de medidas excepcionales en relación con los procedimientos de suspensión de contratos y reducción de jornada por causa de fuerza mayor y por causas económicas, técnicas, organizativas o productivas. Mucho hemos escrito de ellas y de los múltiples problemas que esta regulación ha llevado aparejada. Pero lo cierto es que ese cuerpo de medidas unido a las medidas extraordinarias previstas en materia de cotización y protección contra el desempleo han buscado alcanzar y, a nuestro juicio han conseguido, un adecuado equilibrio entre flexibilidad y seguridad. Además, el Gobierno ha contribuido a reforzar las situaciones de especial debilidad contractual al establecer, por un lado, la limitación de despidos por causa del COVID-19 y, por otro, la interrupción del cómputo de la duración máxima de los contratos temporales.

El Real Decreto-ley 18/2020, de 12 de mayo, de medidas sociales en defensa del empleo (en adelante, "RDL 18/2020"), según recuerda su Exposición de Motivos, "producto del diálogo social y el acuerdo alcanzado entre los agentes sociales y el Gobierno el día 8 de mayo de 2020, día del primer centenario del Ministerio de Trabajo", vino a prorrogar el modelo diseñado en sus precedentes. De modo que, como sigue diciendo la citada Exposición, las medidas en él establecidas "pretenden dar una respuesta adecuada para que las empresas adopten los ajustes dinámicos necesarios que les permitan transitar hasta un escenario de "nueva normalidad", salvaguardar el empleo y proteger especialmente a las personas trabajadoras".

Centrándonos en los ERTES por fuerza mayor, la regulación propicia unos "ERTES de transición" o de "continuación", en la terminología acuñada por Gómez Abelleira, con dos vías de actuación: una llamada "fuerza mayor total" y otra llamada "fuerza mayor parcial" (Fuerza mayor total y parcial: los ertes de transición, El Foro de Labos, 5 de junio de 2020). Son denominaciones, como ha señalado el citado autor, algo desorientadoras, pues se llama "fuerza mayor total" a una simple continuación sin cambios del ERTE de fuerza mayor; mientras que la categoría de la "fuerza mayor parcial" engloba todo ERTE de fuerza mayor en que antes o después del 13 de mayo se haya producido una "recuperación parcial" de la actividad empresarial. El alcance de esta recuperación y su obligatoriedad para las empresas ha generado numerosas dudas. La norma establece un sistema de incentivos para fomentar la reincorporación progresiva de los trabajadores y, por ende, la reactivación económica a un ritmo acorde con el interés general. A tal efecto se introduce un bonus- 
malus articulado a través de la exoneración parcial de las cotizaciones a la Seguridad Social para los trabajadores reincorporados y la reducción en la exoneración de las cotizaciones para el resto de la plantilla en las empresas con un ERTE parcial.

Este camino ha sido seguido también por el RDL 24/2020. A tal efecto, para las empresas que aún tengan problemas para reiniciar la actividad en alguno de sus centros de trabajo, se conserva la figura de ERTE de transición para los casos en los que todos los trabajadores del centro de trabajo continúan suspendidos. En este caso, las exoneraciones serán decrecientes. Se prorrogan los ERTE de fuerza mayor para las empresas que reincorporen a parte de su plantilla aunque se borra del mapa el concepto de "fuerza mayor parcial". En estos casos, la nueva norma establece un sistema de desescalado que mantiene el espíritu de su antecesora de bonificar más a las empresas por los trabajadores activados que a los que se quedan suspendidos. Los procedimientos de regulación temporal de empleo basados en causas económicas, técnicas, organizativas y de producción derivadas del COVID-19 iniciados antes y tras la entrada en vigor del RDL 24/2020, siempre y cuando, en este último caso, sean inmediatamente consecutivos a un ERTE de fuerza mayor, y hasta el 30 de septiembre de 2020 se podrán acoger a las condiciones en materia de exoneraciones a la cotización de los ERTE por fuerza mayor. Además, se incluye un nuevo tipo de ERTE para casos excepcionales en los que una empresa tenga que cerrar su centro de trabajo como consecuencia de un rebrote de la pandemia.

La nueva prórroga de los ERTES hasta el mes de septiembre es el camino para conservar el empleo en sectores que como los relacionados con el turismo, la hostelería, el ocio y el comercio, se han visto particularmente afectados por las medidas adoptadas para limitar la incidencia de la pandemia y que concentran, nada más y nada menos, que un 19,6\% del total del empleo en España.

\section{Bajo la negra sombra del Barón de Rothschild}

El coste económico del conjunto de medidas sociales que ha llevado consigo la conservación de un número tan importante de empleos está resultando enorme. Ello explica que el Gobierno partiera de "la necesidad de implementar todos los mecanismos de control y de sanción necesarios, con el fin de evitar el uso fraudulento de los recursos públicos para finalidades ajenas a las vinculadas con su naturaleza y objetivo" y recuerde el negro camino de aquellos que, como Barón de Rothschild ("Cuando haya sangre en las calles, compra propiedades"), puedan tener la tentación de obtener ventaja y beneficio en una situación tan dramática. El modelo construido para evitar dichos efectos actúa en múltiples niveles.

En primer lugar, a través de un sistema de cargas administrativas cuya representación más evidente es el compromiso de empleo. La DA 6a del RDL 8/2020, en las sucesivas redacciones que dicha disposición ha tenido, ha terminado estableciendo que las medidas extraordinarias en el ámbito laboral y, en particular, la exoneración de las cuotas empresariales en los expedientes derivados de fuerza mayor y, tras el RDL 24/2020 también en los derivados de causas empresariales se encuentran sometidos a la obligación de mantener el empleo durante el plazo de seis meses. Un compromiso cuyo alcance y consecuencias suscitan numerosos interrogantes. Técnicamente, el compromiso de empleo debe ser considerado como una cláusula accesoria que se incorpora a la decisión administrativa que concede la exoneración de cuotas. La doctrina administrativista ha admitido la posibilidad de que los actos administrativos queden sometidos a modos o cargas que no integran el contenido del derecho sino que constituyen obligaciones que se añaden al derecho otorgado y cuyo incumplimiento da lugar a sanciones de diverso orden.

Otra pieza añadida al sistema ha venido de la mano de la prohibición de acogerse a los ERTEs regulados art. 5 RDL 18/2020 por aquellas empresas y entidades que tengan su domicilio fiscal 
en países o territorios calificados como paraísos fiscales. El mismo alcance posee el hecho de que las sociedades mercantiles u otras personas jurídicas que se acojan a los expedientes de regulación temporal de empleo regulados la referida norma y que utilicen los recursos públicos destinados a los mismos no puedan proceder al reparto de dividendos correspondientes al ejercicio fiscal en que se apliquen estos ERTE, excepto si abonan previamente el importe correspondiente a la exoneración aplicada a las cuotas de la Seguridad Social. Cómo debe producirse, llegado el caso, esa reintegración y cuáles son los efectos de la decisión de reparto son dudas no resueltas. En todo caso, esta limitación a repartir dividendos no será de aplicación para aquellas entidades que, a fecha de 29 de febrero de 2020, tuvieran menos de 50 personas trabajadoras, o asimiladas a las mismas, en situación de alta en la Seguridad Social.

Pero el mecanismo más poderoso es el contenido en la DA 2º RDL 9/2020. Dicha disposición crea un particular procedimiento de reintegro de prestaciones indebidas en vía sancionadora en el que las entidades gestoras quedan en un discreto segundo plano. La insuficiencia del modelo propuesto requerirá un futuro desarrollo reglamentario. El Gobierno ahora se limita a esbozarlo. Establece a tal fin la responsabilidad directa de la empresa sobre la clave de bóveda que proporciona el también reformado art. 43.3 LISOS. De este modo, "el reconocimiento indebido de prestaciones a la persona trabajadora por causa no imputable a la misma, como consecuencia de alguno de los anteriores incumplimientos dará lugar a la devolución de las prestaciones indebidamente generadas. En tales supuestos, la empresa deberá ingresar a la entidad gestora las cantidades percibidas por la persona trabajadora de acuerdo con lo establecido en la LISOS". Cómo deba "ingresarse a la entidad gestora" es cuestión no resuelta. En fin, dentro de la cascada de cambios que, como hemos señalado, caracteriza esta normativa ha desaparecido la referencia que contenía en su primera redacción esta norma a la "revisión de oficio del acto de reconocimiento de dichas prestaciones". Y, también, ha desaparecido del texto anterior: "sin perjuicio de la responsabilidad administrativa o penal que legalmente corresponda (...)".

\section{Tecnología y COVID-19}

La crisis del COVID-19 ha dotado de nuevo protagonismo a las fórmulas de teletrabajo. Muchas empresas han tenido que improvisar soluciones. De pronto ya no es una promesa de futuro, sino una tabla de salvación. Si, según los datos del INE, en 2019 apenas un 4,8\% de los españoles trabajó más de la mitad de los días desde casa (muy por debajo, por ejemplo, del 14\% de los holandeses o del 13,3\% de los finlandeses), la pandemia obligó, casi en cuestión de horas, a disparar este porcentaje hasta el 34\% del total de la población activa.

El art. 5 del RDL 8/2020 apostó decididamente por el establecimiento de sistemas de organización que permitiesen mantener la actividad por mecanismos alternativos al trabajo presencial, particularmente, por medio del trabajo a distancia, debiendo la empresa adoptar las medidas oportunas si ello es técnica y razonablemente posible y si el esfuerzo de adaptación necesario resulta proporcionado. Se trata de una norma de contenido laboral que desplaza de manera temporal lo previsto en el art 13 ET y, parcialmente, en el art. 16 LPRL. Como resulta de las exposiciones de motivos tanto del RDL 8/2020 como del RDL 15/2020, en la crisis del COVID-19 el teletrabajo constituye un medio preferente para garantizar la continuidad de la actividad empresarial, para garantizar las medidas de contención y la protección de las personas trabajadoras y para seguir atendiendo a las necesidades de conciliación de la vida laboral y familiar. El art. 7.1 e) del RDL 21/2020 continúa esta línea cuando señala que las empresas deberán: "Adoptar medidas para la reincorporación progresiva de forma presencial a los puestos de trabajo y la potenciación del uso del teletrabajo cuando por la naturaleza de la actividad laboral sea posible”. 
El paso del modelo de "teletrabajo de emergencia" a un modelo estable de trabajo a distancia es una cuestión pendiente. Bajo el "espíritu" del Acuerdo Marco Europeo, el Gobierno ya tiene entre manos el Anteproyecto de Ley Reguladora del Trabajo a Distancia. Muchas son las singularidades de esta disposición en ciernes (ahora en período de consultas), pero dos destacan entre ellas: los trabajadores que se encuentren fuera de la oficina podrán negociar su horario con el empleador -con excepciones y siempre y cuando se cumplan unos requisitos- y, por otro lado, la empresa deberá cargar con todos los costes que cause el empleado durante su actividad en el domicilio o fuera de la oficina.

Pero la tecnología no solo ha desarrollado el teletrabajo. La biometría se ha proyectado sobre fronteras en la era del COVID-19. La identidad biológica es propia de cada sujeto y, por tanto, cualquier instrumento que la utilice permitirá, a quien de él se sirva, internarse en el terreno más recóndito que cada ser humano tiene. Podría decirse que, a su través, se puede entrar en la intimidad de la intimidad. Ese carácter invasivo entrańa numerosos riesgos para la dignidad humana, riesgos que alcanzan mayor voltaje si tenemos en cuenta que el uso de los sistemas biométricos se está convirtiendo, por momentos, en una potente herramienta de control. Un control que se extiende sobre todas las facetas de la vida dado que esta información sirve, unas veces como un mecanismo sencillo, gratuito y seguro para blindar nuestras transacciones bancarias pero también, en la era del COVID-19, se está convirtiendo en instrumento para los pasaportes serológicos. En algunos países, como recoge el estudio realizado por la AEPD titulado "El uso de las tecnologías en la lucha contra el COVID19. Un análisis de costes y beneficios", ha empezado a considerarse el uso de apps equivalentes a lo que sería un pasaporte, mostrando en pantalla un código de colores o un código QR, para que un vigilante o un sistema de control de acceso pueda permitir circular o no al portador.

Detrás de todo ello está el Big data. Los datos de salud, los datos biométricos, en suma los datos personales sensibles, son fuentes esenciales para el control del COVID-19. Pero, como se puede deducir de las múltiples interpretaciones que viene realizando la Agencia Española de Protección de Datos, la normativa reguladora del derecho fundamental a la protección de datos personales no conoce de excepciones. Y es que, como al comienzo de esta pandemia dejó sentado en el Informe 0017/2020: "la normativa de protección de datos personales, en tanto que dirigida a salvaguardar un derecho fundamental, se aplica en su integridad a la situación actual, dado que no existe razón alguna que determine la suspensión de derechos fundamentales, ni dicha medida ha sido adoptada”.

Es evidente que la transformación tecnológica lleva consigo un alejamiento de lo colectivo, una especie de desagregación que se traduce en una manifiesta ruptura de la unidad de acción colectiva que se une a un proceso continuado. La intrínseca dispersión geográfica que conduce a su atomización no deja de ser un caldo de cultivo idóneo para el extrañamiento respecto de los representantes de los trabajadores en general y, en consecuencia, para la individualización de las relaciones laborales. Uno de los riesgos del teletrabajo. Pero también es cierto que esta nueva realidad abre nuevos espacios a los sujetos colectivos. Muestra de ello es el nuevo modelo de representación inaugurado por el art. 23 RDL 8/2020 y, por extensión, la expansión de los períodos digitales de consultas y negociación como clara representación este tiempo nuevo.

\section{COVID-19: entre la precaución y la prevención}

El denominado "principio de precaución" puede ser formulado del siguiente modo: "Cuando una actividad se plantea como una amenaza para la salud humana o el medio ambiente, deben tomarse medidas precautorias aun cuando algunas relaciones de causa y efecto no se hayan establecido de 
manera científica en su totalidad". El mismo supone una de las transformaciones más profundas en las técnicas de tutela de la seguridad y salud en el trabajo. Su ámbito de aplicación es la incertidumbre científica, es decir, se aplica en el supuesto de riesgo incierto o potencial. En la era del COVID-19 la referencia a este principio resulta fundamental.

Desde la perspectiva de la seguridad y salud, el riesgo laboral presente en todo centro de trabajo se ańade el riesgo de salud pública derivado del riesgo general de contagio del COVID-19. En este sentido, el Criterio Técnico de la Inspección de Trabajo y Seguridad Social 102/2020 sobre medidas y actuaciones de la Inspección de Trabajo y Seguridad Social relativas a situaciones derivadas del nuevo Coronavirus, diferencia, a efectos de actuación de la ITSS (cuya actuación se vincula estrechamente al cumplimiento de las normas laborales), dos categorías de centros de trabajo. Así, el Criterio diferencia aquellos centros de trabajo en los que su actividad por sí misma supone un riesgo de exposición al COVID-19 (por ejemplo, la sanitaria) de las demás actividades productivas en las que su actividad no lleva inherente el riesgo biológico de ser contagiado por el COVID-19, entre las que se encontraría la construcción. En las primeras, el riesgo de contraer el coronavirus se califica como un riesgo laboral, mientras que en las segundas no se considera riesgo laboral.

En todo caso, el riesgo existe y en ocasiones sería muy difícil poner puertas al campo. En todo caso, la precaución debe estar presente y, para ello, los centros de trabajo deberán cumplir estrictamente con las garantías establecidas por el art. 7 del RDL 21/2020: (i) Reincorporación progresiva (ii) Adoptar medidas de ventilación, limpieza y desinfección adecuadas a las características e intensidad de uso de los centros de trabajo, con arreglo a los protocolos que se establezcan en cada caso; (iii) Adaptar las condiciones de trabajo, incluida la ordenación de los puestos de trabajo y la organización de los turnos (iv) Evitar la coincidencia masiva, etc...

En el ámbito europeo, donde se echaba de menos alguna respuesta, la Declaración de la Comisión tras la presentación de la Directiva (UE) 2020/739 de la Comisión al Parlamento Europeo y al Consejo en lo que respecta a la prevención y la protección de la salud y la seguridad de los trabajadores expuestos o que puedan estar expuestos al COVID-19, de 26 de junio de 2020, ha querido dar cierta luz en esta materia. Así, la Comisión considera que, al incluir al SARS-CoV-2, el coronavirus causante de la COVID-19, en el anexo III de la Directiva 2000/54/CE del Parlamento Europeo y del Consejo sobre agentes biológicos, la Directiva (UE) 2020/739 de la Comisión se mejora significativamente el nivel de protección existente, en particular en lo que se refiere a la protección de los trabajadores de primera línea.

La Comisión ha recordado también que, en lo que se refiere a la salud y la seguridad en el trabajo, "la Directiva marco 89/391/CEE del Consejo impone a todos los empresarios la obligación no negociable de llevar a cabo y mantener una evaluación de riesgos completa y actualizada, con arreglo a sus artículos 6 y 9. Ello implica que todos los riesgos en el lugar de trabajo, entre ellos la exposición al COVID-19, deben tenerse en cuenta y evaluarse conjuntamente, incluida su interacción con los riesgos psicosociales, biológicos, químicos y de otro tipo".

Igualmente, subraya que, "en consecuencia, se adoptarán las medidas preventivas y de protección pertinentes, también en el caso específico de una posible exposición al COVID-19, y que el empresario facilitará toda la información necesaria sobre todos los riesgos para la seguridad y la salud, así como sobre todas las medidas y actividades de protección y prevención que afecten tanto a la empresa y/o al establecimiento en general, como a cada tipo de puesto de trabajo y/o de función". Y, en fin, se recuerda "la gran importancia de una formación adecuada de los trabajadores que puedan estar expuestos al SARS-CoV-2 y el derecho de cada trabajador a recibir dicha formación, en particular en forma de información e instrucciones específicas para su puesto de trabajo o función”. 


\section{Socialización de los riesgos como objetivo}

El COVID-19 nos está enfrentando a un escenario de enorme incertidumbre. Ante la magnitud del problema, los Gobiernos han respondido adoptando medidas de muy diverso orden que en lo social han pasado por garantizar un flujo de rentas para los agentes cuyas fuentes de ingresos se han visto perjudicadas más directamente por la epidemia. Pero la verdad es que "la mayoría de las recomendaciones de seguridad que se han mandado desde los gobiernos a la población presuponen que esta tiene casa propia (para confinarse en ella), agua corriente (para lavarse las manos con ella), guantes y mascarillas (para tocar y respirar a través de ellas) y acceso a internet (para teletrabajar y ser espiado por medio de él): lujos insólitos para los más pobres" (M. GALINDO, "Desobediencia, por tu culpa voy a sobrevivir”, en AA. VV., Sopa de Wuhan, ASPO, 2020, p. 120).

En este incierto momento, la Renta Básica Universal se ha puesto, una vez más, sobre la mesa. Economistas, juristas, sociólogos e, incluso, filósofos vienen proponiendo desde hace años un conjunto de medidas de esencia redistributiva denominadas "renta universal", "subsidio universal", "ingreso mínimo de existencia” o incluso "ingreso de ciudadanía”. Se trataría de avanzar, más allá de la solidaridad y superando el Estado del bienestar, instaurando un sistema, enormemente ambicioso, de tutela social a través del reparto de los recursos de cualquier naturaleza de los que dispone la sociedad. A través del mismo se pretende asegurar a todos los individuos un ingreso suficiente para satisfacer sus necesidades básicas. Un modelo que vendría caracterizado por asignar a toda persona, desde su nacimiento y hasta su muerte, un subsidio que estaría totalmente desconectado de cualquier obligación o condición previa y que se encontraría definido por los principios de universalidad, incondicionalidad e individualización.

En nuestro país, la normativa de apoyo al empleo y a las rentas de hogares vulnerables como consecuencia del COVID-19, ha comenzado a acelerar los ensayos de modelos de rentas básicas para atender las necesidades de colectivos de trabajadores que no pueden acceder a las prestaciones por desempleo. El RDL 11/2020, por el que se adoptan medidas urgentes complementarias en el ámbito social y económico para hacer frente al COVID-19, vino a establecer un primer ensayo de renta básica en relación con los trabajadores temporales y con las empleadas del hogar. Pero la gran cuestión era la de si debía darse un paso más, estableciendo una Renta Básica Universal que sirviera para dar respuesta al tsunami de desempleo que amenaza con arrasar nuestro sistema productivo. En este contexto, cobró nuevo protagonismo el compromiso alcanzado en el acuerdo de Gobierno entre PSOE y Unidas Podemos para desarrollar un "Ingreso Mínimo Vital como prestación de Seguridad Social". Las palabras no están huérfanas de significado y no es lo mismo un "ingreso mínimo vital" que una "renta básica universal".

Finalmente, esta sugerente propuesta que quizá debería encontrar en su día el adecuado refrendo constitucional, se ha materializado en el Real Decreto-ley 20/2020, de 29 de mayo, por el que se establece el ingreso mínimo vital. Con esta pieza se da un paso de enorme importancia en la evolución del sistema de Seguridad Social, un verdadero hito histórico que dota de especial protagonismo al nivel no contributivo de la Seguridad Social. Con todo, el ingreso mínimo vital busca unir con su acción presente y futuro. Tal y como señala su Exposición de Motivos, el objetivo es que esta política actúe "como un seguro colectivo frente a los retos que nuestras sociedades enfrentarán en el futuro próximo: carreras laborales más inciertas, nuevas vulnerabilidades como la puesta de manifiesto por la crisis de COVID-19, transformaciones económicas asociadas a la robotización o el cambio climático, y en general una mayor volatilidad en los ingresos y los empleos, problemas frente a los que casi nadie será inmune, pero que afectarán especialmente a los grupos sociales más vulnerables". El ingreso mínimo vital se configura como el derecho subjetivo a una prestación de naturaleza económica que garantiza un nivel mínimo de renta a quienes se encuentren en situación de vulnerabilidad económica articulada 
a través de un modelo de gobernanza compartida en la que de forma coordinada participan el Estado, las comunidades autónomas y las entidades locales.

Pero la pregunta sigue en pie: ¿el modelo que ahora incorpora el Gobierno crea una renta básica universal o constituye un sistema de protección frente a la pobreza extrema? Más parece lo segundo que lo primero. El modelo busca una última red de seguridad económica que ofrece protección a los hogares cuyos recursos son insuficientes. Si los rasgos que definen la renta básica son la universalidad, la incondicionalidad y la individualización, un modelo como el propuesto no se adapta a tales rasgos caracterizadores. Un progreso notable en la consecución de esa poderosa idea de una renta de subsistencia por el hecho de nacer. Pero lo que parece claro es que debemos seguir caminando...

\section{Interrogantes de futuro: Atravesando la incertidumbre}

La era del COVID-19 abre tiempos imprevisibles, como imprevisibles serán las respuestas que puedan dar los mercados de trabajo a esta nueva situación. En esa respuesta será, en todo caso, esencial el papel de los agentes sociales. El diálogo y el acuerdo con el Gobierno son fundamentales para generar una normativa que incentive la actividad empresarial, el mantenimiento del empleo y la protección de los trabajadores. La negociación colectiva tendrá mucho que decir en todos los aspectos porque en tiempos tan turbulentos como los que vivimos será bueno que la sociedad busque un camino conjunto. En esta ocasión tenemos un enemigo común y sería bueno que nadie lo perdiera de vista.

Deberán buscarse soluciones imaginativas que eviten, en todo caso, la destrucción masiva de empleo. Probablemente deberemos pensar en posibles migraciones de empleo entre sectores de actividad. Ello conlleva la necesidad de apoyar la formación en determinadas habilidades de los potenciales desempleados de los sectores más afectados por la pandemia para poder facilitar así su tránsito hacia nuevos puestos de trabajos. Un reciente informe del Banco de España ponía de manifiesto que los trabajadores de las ramas más afectadas, la proporción de mujeres, de jóvenes y de colectivos con menos formación, escasa experiencia y contratos temporales es especialmente elevada.

Atravesar lo incierto es un viaje inesperado en el que lo que dejamos atrás tampoco son certezas. Probablemente, todos nos preguntamos las mismas cosas: ¿se producirán nuevos rebrotes?, ¿cuándo acabará esta "nueva normalidad"?, ¿cuándo tendremos una vacuna que nos regrese a la sociedad que perdimos?, ¿cuánto tiempo soportará la sociedad este camino? Lo cierto es que, frecuentemente, cuando salimos de una incertidumbre solemos llegar a otra, por eso el camino que recorremos es fundamental para determinar el futuro al que arribaremos. 